\title{
The first seven years of nationally organized helicopter emergency medical services in Finland - the data from quality registry
}

Anssi Saviluoto ${ }^{1,2^{*}}$ (D) Johannes Björkman ${ }^{1,3+}$, Anna Olkinuora ${ }^{1}$, Ilkka Virkkunen ${ }^{1}$, Hetti Kirves ${ }^{4}$, Piritta Setälä ${ }^{5}$, Ilkka Pulkkinen ${ }^{1}$, Päivi Laukkanen-Nevala ${ }^{1}$, Lasse Raatiniemi ${ }^{6}$, Helena Jäntti ${ }^{2,7}$, Timo lirola $^{8}$ and Jouni Nurmi ${ }^{1,9}$

\begin{abstract}
Background: Helicopter Emergency Medical Services (HEMS) play an important role in prehospital care of the critically ill. Differences in funding, crew composition, dispatch criteria and mission profile make comparison between systems challenging. Several systems incorporate databases for quality control, performance evaluation and scientific purposes. FinnHEMS database was incorporated for such purposes following the national organization of HEMS in Finland 2012. The aims of this study are to describe information recorded in the database, data collection, and operational characteristics of Finnish HEMS during 2012-2018.

Methods: All dispatches of the six Finnish HEMS units recorded in the national database from 2012 to 2018 were included in this observational registry study. Five of the units are physician staffed, and all are on call 24/7. The database follows a template for uniform reporting in physician staffed pre-hospital services, exceeding the recommended variables of relevant guidelines.

Results: The study included 100,482 dispatches, resulting in 33,844 (34\%) patient contacts. Variables were recorded with little or no missing data. A total of 16,045 patients (16\%) were escorted by HEMS to hospital, of which 2239 (2\%) by helicopter. Of encountered patients 4195 (4\%) were declared deceased on scene. The number of denied or cancelled dispatches was 66,638 (66\%). The majority of patients were male $(21,185,63 \%)$, and the median age was 57.7 years. The median American Society of Anesthesiologists Physical Scale classification was 2 and Eastern Cooperative Oncology Group performance class 0. The most common reason for response was trauma representing 26\% (8897) of the patients, followed by out-of-hospital cardiac arrest 20\% (6900), acute neurological reason excluding stroke 13\% (4366) and intoxication and related psychiatric conditions 10\% (3318). Blunt trauma (86\%, 7653) predominated in the trauma classification.

(Continued on next page)
\end{abstract}

\footnotetext{
* Correspondence: anssi.saviluoto@finnhems.fi

${ }^{\dagger}$ Anssi Saviluoto and Johannes Björkman contributed equally to this work.

'Research and Development Unit, FinnHEMS, WTC Helsinki Airport, Lentäjäntie 3, FI-01530 Vantaa, Finland

2University of Eastern Finland, PO Box 1627, Fl-70211 Kuopio, Finland

Full list of author information is available at the end of the article
}

(C) The Author(s). 2020 Open Access This article is licensed under a Creative Commons Attribution 4.0 International License, which permits use, sharing, adaptation, distribution and reproduction in any medium or format, as long as you give appropriate credit to the original author(s) and the source, provide a link to the Creative Commons licence, and indicate if changes were made. The images or other third party material in this article are included in the article's Creative Commons licence, unless indicated otherwise in a credit line to the material. If material is not included in the article's Creative Commons licence and your intended use is not permitted by statutory regulation or exceeds the permitted use, you will need to obtain permission directly from the copyright holder. To view a copy of this licence, visit http://creativecommons.org/licenses/by/4.0/ The Creative Commons Public Domain Dedication waiver (http://creativecommons.org/publicdomain/zero/1.0/) applies to the data made available in this article, unless otherwise stated in a credit line to the data. 
(Continued from previous page)

Conclusions: Gathering detailed and comprehensive data nationally on all HEMS missions is feasible. A national database provides valuable insights into where the operation of HEMS could be improved. We observed a high number of cancelled or denied missions and a low percentage of patients transported by helicopter. The medical problem of encountered patients also differs from comparable systems.

Keywords: Air ambulances, Emergency medical services, Critical care, Registries, Trends, Quality indicators

\section{Background}

Helicopter Emergency Medical Services (HEMS) play an important role in prehospital care of the critically ill in many Emergency Medical Services (EMS) around the world. However, little is known about when and where the utilization of this expensive resource is beneficial [13]. Organization of HEMS varies considerably between countries and states. Differences in funding, composition of crew, emergency dispatch, patient population, hospital network and geographical characteristics make the applicability of study results and comparison between services challenging [3]. Consequently, accurate and comprehensive data is a prerequisite for the development and improvement of any service [4].

Quality registries are a valuable source of data when evaluating the performance of any field in health care $[4$, 5]. For this purpose, several HEMS systems utilize databases to collect and analyze mission data [6-8]. To enable multi-center research and comparison between systems, guidelines for data collection have been published for prehospital airway management $[9,10]$., cardiac arrest [11, 12]. and physician-staffed emergency medical services (P-EMS) [13, 14]. Since 2012 HEMS operations have been nationally organized. At the start of the national service, a database called FinnHEMS database (FHDB) was established to record detailed information on all HEMS missions in the country. FHDB has been adjusted to conform with the previously stated guidelines, but it also stores additional information not required by the guidelines.

Owing to a nationally organized and documented HEMS, FHDB gives a comprehensive view of the whole system. The aims of this study are 1) to describe the data collected into FHDB and evaluate the completeness of the data. 2) To describe the operational and patient characteristics of HEMS in Finland during the first 7 years of nationally organized and documented HEMS.

\section{Methods}

\section{Study design}

This was an observational registry study, describing all HEMS dispatches in Finland during 1.1.2012-31.12.2018. Study permission was requested and granted by all the participant hospital districts (Oulu University Hospital 200/2019 2.7.2019, Helsinki University Hospital HUS/
280/2019 9.7.2019, Turku University Hospital J30/19 4.8.2019, Hospital District of Lapland 32/2019 22.8.2019, Kuopio University Hospital RPL 102/2019 22.8.2019, Tampere University Hospital RTL-R19580 2.9.2019). According to Finnish Law, ethical permission is not required for observational studies. However, due to the large amount of data, including sensitive patient data, ethical permission was requested and granted by the Ethical Board of the University of Helsinki (HUS/3115/2019 $\$ 194)$. STROBE guidelines are followed in reporting of the study [15].

\section{Setting}

Finland is a Nordic country with a population of 5.5 million and an area of $338,424 \mathrm{~km}^{2}$, thus making it the most sparsely populated country in the European Union. Healthcare is governed regionally by 21 hospital districts, each braced by one of the five university hospitals for tertiary care.

EMS in Finland are locally organized by the hospital districts. The system is publicly funded, including the dispatch centers and HEMS. Since 2012 HEMS is administered by a national administrative unit FinnHEMS Ltd., owned and governed by the five university hospitals during the study period. A few central hospitals have also organized physician staffed rapid response cars to support the local EMS.

Emergency calls are all made to a national emergency number 112 (healthcare, fire, police \& social services). The calls are processed by Emergency Response Centre Operators (ERCO) in one of the six regional dispatch centers using a nationally unified, tiered dispatch structure assisting in the dispatch of units, with slight local variations. ERCOs are specially educated for the task but they are not healthcare providers. In addition to being alarmed by the dispatch centers, the HEMS units can also be requested by the EMS crews. A list of dispatch codes and those leading to HEMS activation can be seen in Additional File 1.

HEMS units are alerted to patients who are thought to benefit from early prehospital intensive care. Typical alarm criteria are Out-of-Hospital Cardiac Arrest (OHCA), major trauma and unconsciousness with an unknown origin. In the Finnish EMS system, HEMS units are not normally dispatched to conscious stroke 
patients, patients suffering from respiratory failure, and cardiovascular accidents, with the exception of the unit based in Lapland, due to the extremely sparse population and long distances in the area.

Five HEMS units are based at the university hospitals and one in Lapland, and their actual service areas encompassing $95 \%$ of the operations cover nearly the whole population of Finland (Fig. 1) [16, 17]. The three southernmost units operate with Airbus H135 and the three other units with Airbus H145 helicopters. The primary task of the HEMS units is prehospital care, with rare interhospital transfers and search-and-rescues being decided upon in a case-by-case fashion.

The HEMS units operating out of the university hospitals are staffed by a physician, a HEMS Crew Member (HCM; either a paramedic or a firefighter according to local regulations) and a pilot, while the unit in Lapland has two advanced level flight paramedics and two pilots. Physicians in the HEMS units are mainly anesthesiologists with sub specialization in prehospital critical care whereas HCMs are specially trained in prehospital critical care as well as in aviation. The HEMS pilots have significant previous experience in either civilian or military helicopter operations.

The wide array of equipment and medications used in the HEMS units is not nationally standardized but locally governed by the hospital districts. All units are oncall 24/7/365 and are capable of flying under instrument flight rules and night-time flight operations using night vision goggles. Rapid response vehicles are available for the HEMS crews in every base for short-range missions or for when weather conditions don't meet the HEMS minima for airborne operations.

\section{FinnHEMS database}

As stated previously, the data variables recorded in FHDB follow a template for uniform reporting in physician staffed pre-hospital services according to relevant guidelines [9-14]. A list of the current central variables and their response rate is shown in Additional File 2, also depicting compulsory variables. Over the years there have been minor revisions in the datasets, presented in Additional File 3. FHDB is used for daily reporting, scientific purposes and the governing of HEMS operations as a whole [16, 18-20]. The database also allows the creation of specific casereport forms for research projects or to monitor effects of specific quality improvement interventions. The database does not allow extremely abnormal values that are clearly erroneous, but it does not interfere with single erroneous input that are within the normal variation range. Therefore, all input to the database was seen as valid, and clearly erroneous input was also included, since this study describes the database per se and validity thereof, not the actual operational set. In addition, some variables are in selected cases recorded by the first ambulance unit at the scene, which also might affect the validity. During the initial years of FHDB key entered data was not mandatory, this has since been rectified. The data is entered by the physician or paramedic on call promptly following a mission, using a web-based form over a secure connection. However, the entered data is not externally validated by any other person, making errors a possibility. Data input in the web-form is immediately recorded to FHDB.

\section{Statistical methods}

Normally and non-normally distributed continuous data are reported as means with standard deviations (SD) and medians with quartiles (25th percentile and 75th percentile expressed as Q1/Q3), respectively. Categorical variables are reported as percentages with $95 \%$ confidence intervals $(95 \%$ CI). Proportions are reported as \% (n). As this was a descriptive analysis of the entries recorded to the database, no comparisons between any groups were necessary. The data was analyzed using IBM SPSS Statistics 25 (IBM Corporation, Armonk, NY, USA).

\section{Results \\ Subjects}

All 100,482 dispatches recorded into the FHDB between 1.1.2012-31.12.2018 were included in this study (Fig. 2). Multi-patient dispatches $(n=569,0.6 \%)$ were analyzed as one entry per dispatch and not per patient.

\section{Operational mission characteristics}

Of the accepted dispatches, 54\% $(42,059)$ were responded to with a helicopter and $45 \%(35,162)$ with a rapid response vehicle. In the remaining $1 \%$ (739) another mode of transport was used (e.g. Border Guard Helicopter, other vehicle). The main reasons for rapid response vehicle use was short distance $(51 \%, 18,103)$ or weather below HEMS minima criteria $(35 \%, 12,437)$.

A total of $67 \%(66,638)$ of the dispatches were denied or cancelled. These included dispatches that were denied or cancelled due to not requiring HEMS care after additional information on status of the patient was received $(56 \%, 37,542)$, denied or cancelled due to alternative tasking $(14 \%, 9163)$, denied or cancelled due to weather $(10 \%, 6950)$ or denied or cancelled due to technical obstacle $(0.5 \%, 344)$, the remaining $20 \%$ being recorded as "denied or cancelled due to other reason". Annual changes in the proportions are shown in Fig. 3.

Response time from alarm to patient contact was available for all missions where the patient was encountered, and the median was $19 \mathrm{~min}(\mathrm{Q} 1 / \mathrm{Q} 314 / 30 \mathrm{~min}$, 


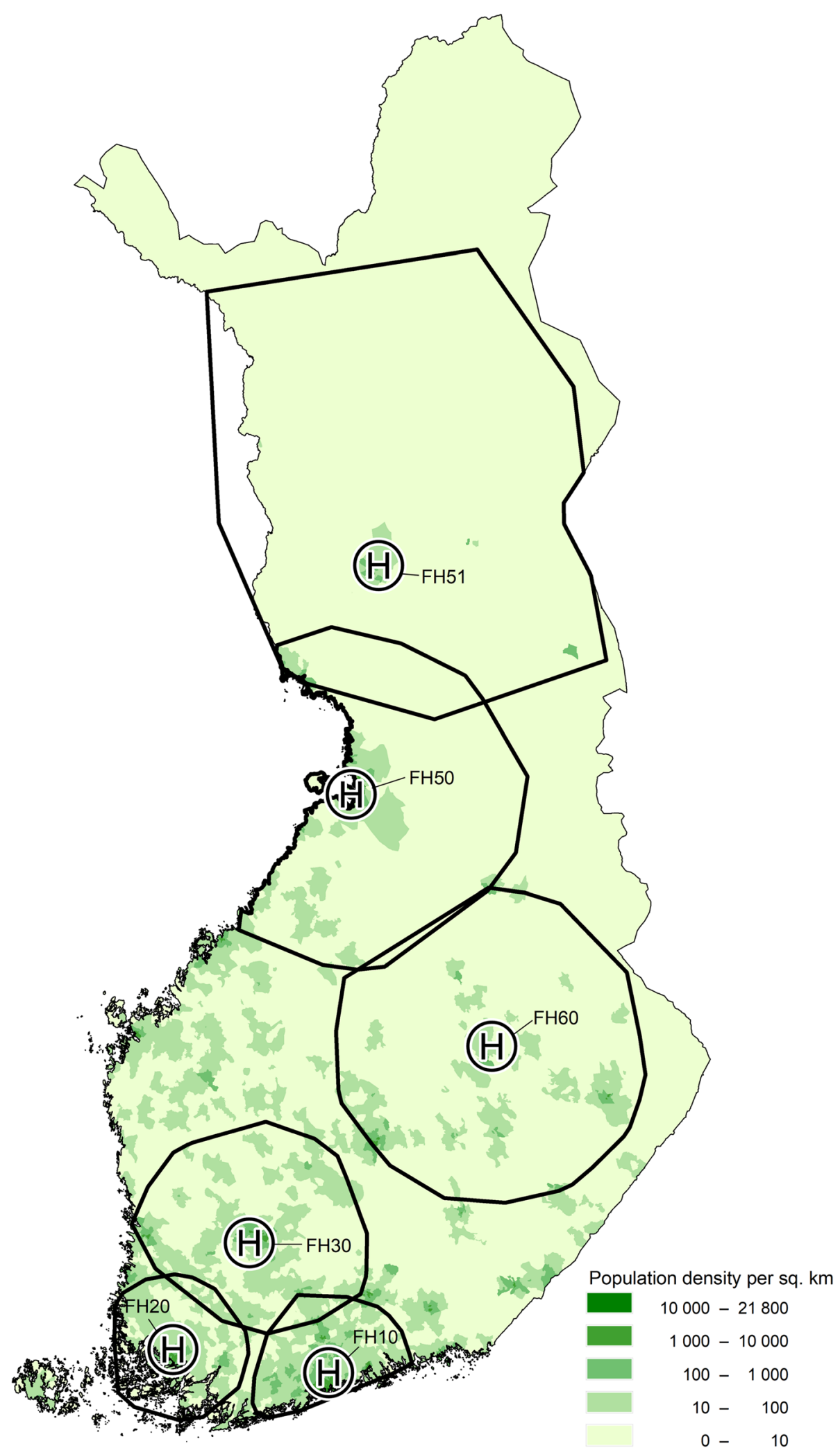

Fig. 1 The population density of Finland, location of HEMS bases and their actual service areas with 95\% of the missions in 2017 [16, 17]. The population density is shown as density (population per $\mathrm{km}^{2}$ ) per postal area. $\mathrm{H}=\mathrm{HEMS}$ base, $\mathrm{FH}=$ FinnHEMS unit 


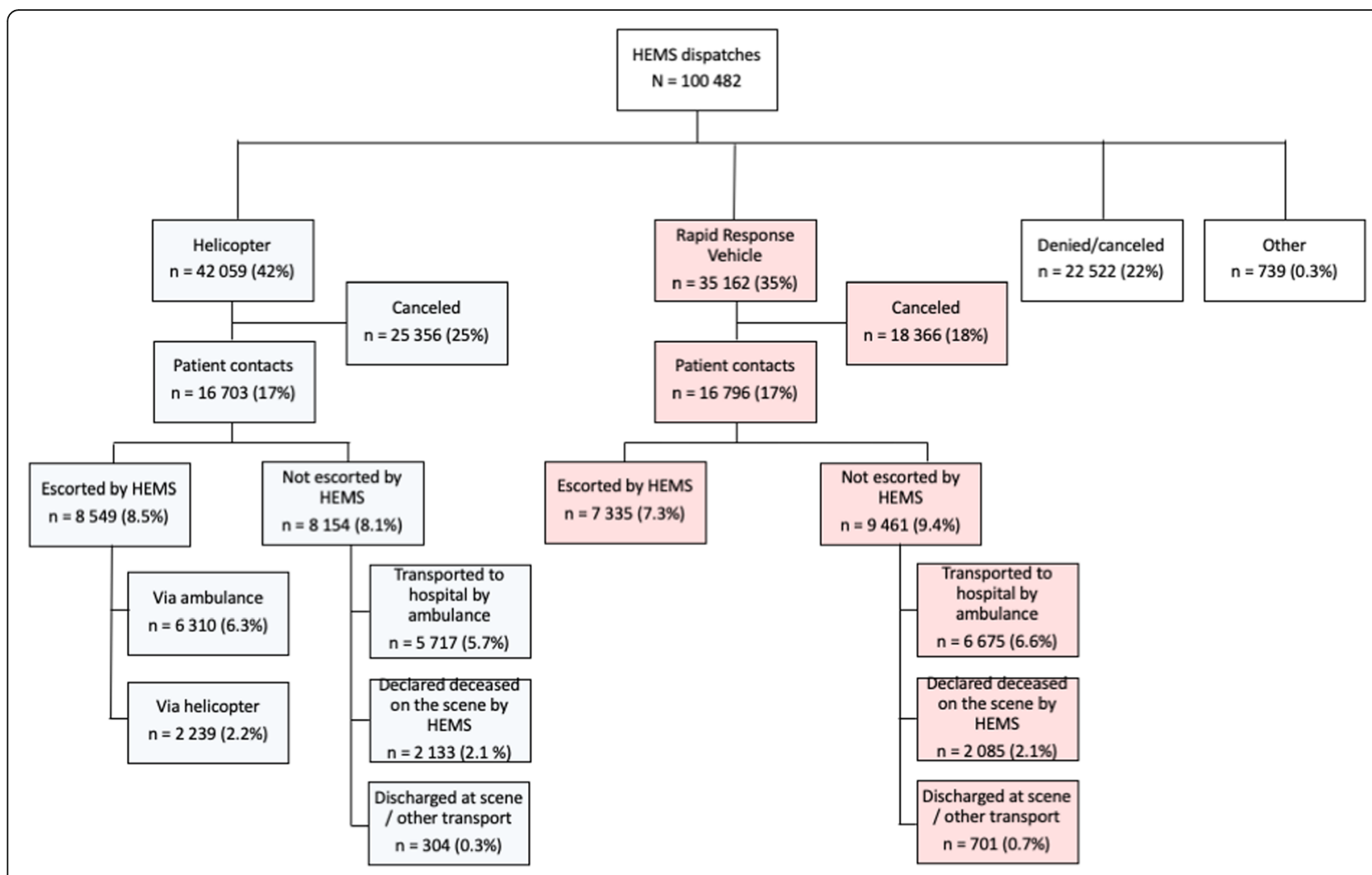

Fig. 2 Diagram of HEMS dispatches. Revisions to FHDB makes it unreliable to discern denied missions from cancelled directly following an alarm. Missions canceled after start of the mission are labelled as "canceled". Percentages are of total N

Fig. 4). On-scene time was available in $94.7 \%(15,255)$ of the missions where the patient was either escorted or transported by HEMS, the median being 23 min (Q1/Q3 $12 / 36 \mathrm{~min})$. Correspondingly, the transport time was available for $92.8 \%(14,969)$ of all dispatches with a median of $25 \mathrm{~min}$ (Q1/Q3 14/41 min).

\section{Patient characteristics}

Of the patients encountered by HEMS, 35\% (12,011) were females and $63 \%(21,185)$ males, with gender reported as "not known" in 2\% (648) of missions. The median age of the patients was 57.7 years (Q1/Q3 33.8/72.0 years) (Fig. 5).

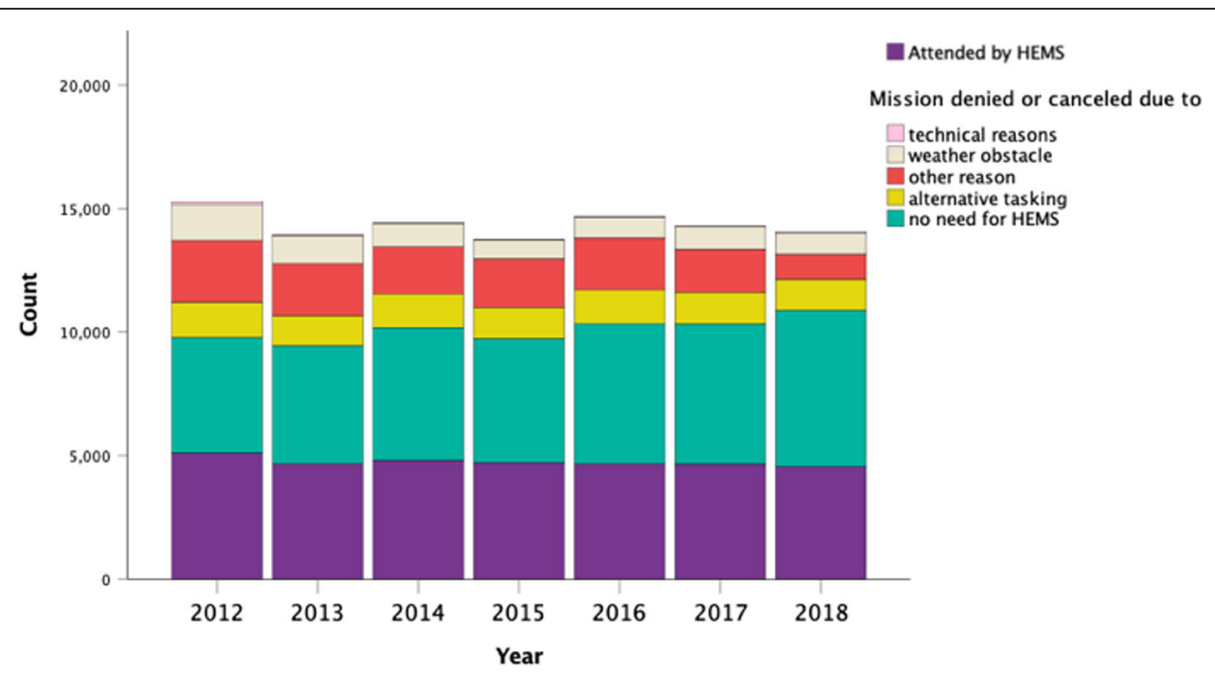

Fig. 3 Annual change in the outcome of the HEMS dispatches 

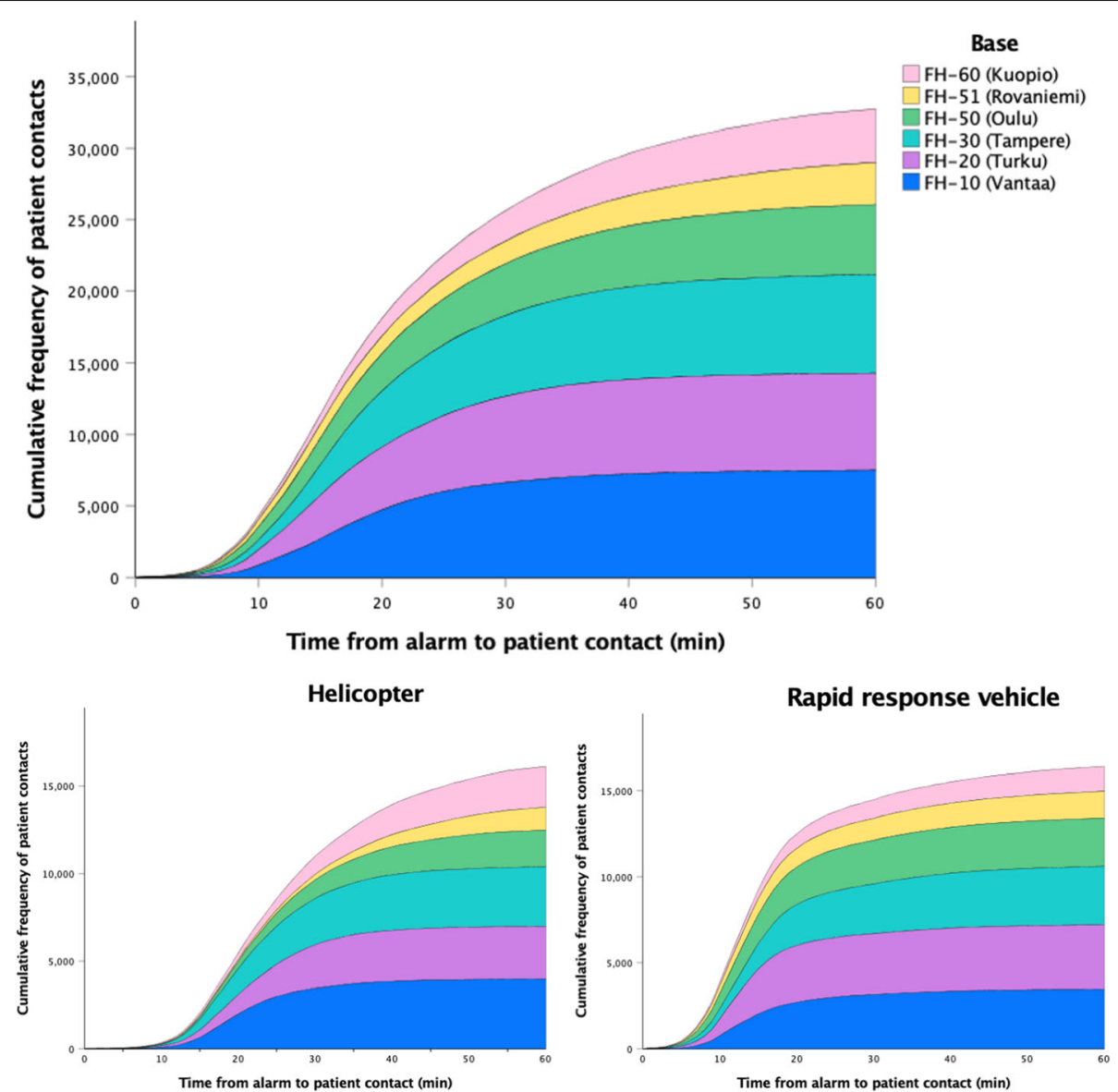

Fig. 4 The cumulative frequency distribution of response time in HEMS bases during 2012-2018 $(n=33,844)$. The median was 25 min when responding with the helicopter and $15 \mathrm{~min}$ with the rapid response vehicle

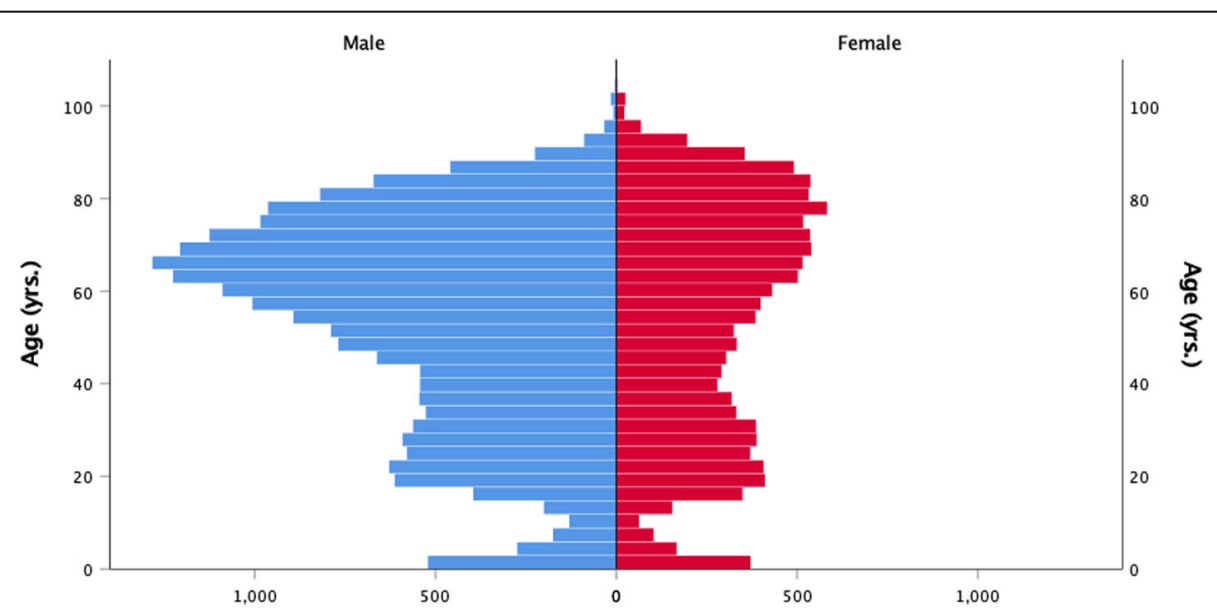

Fig. 5 Age and gender of patients encountered by HEMS 
Table 1 Patient characteristics $(n=33,820)$. ASA-PS Class $=$ American Society of Anesthesiologist Physical Status, ECOG = Eastern Cooperative Oncology Group. Q1/Q3 denotes 25th and 75th percentiles

\begin{tabular}{lllllrl}
\hline & $\mathrm{n}$ & $(\%)$ & Median & $\mathrm{Q} 1 / \mathrm{Q} 3$ & Missing $\mathrm{n}$ & $(\%)$ \\
\hline Age, years & 33,820 & & 57.7 & $33.8 / 72.2$ & 24 & $(0.07)$ \\
Gender, female & 12,011 & $(35.5)$ & & & 648 & $(1.9)$ \\
ASA-PS Class & 30,477 & & 2 & $1 / 3$ & 3367 & $(9.9)$ \\
I & 10,422 & $(30.8)$ & & & & \\
II & 9083 & $(26.8)$ & & & & \\
III & 8098 & $(23.9$ & & & & \\
IV & 2491 & $(7.4)$ & & & & \\
V & 303 & $(0.9)$ & & & & \\
VI & 80 & $(0.2)$ & & & & \\
ECOG & 21,397 & & 0 & $0 / 1$ & 2367 & $(10.0)$ \\
0 & 13,489 & $(18.9)$ & & & & \\
1 & 4126 & $(5.8)$ & & & & \\
2 & 2114 & $(3.0)$ & & & & \\
3 & 1375 & $(1.9)$ & & & & \\
4 & 293 & $(0.4)$ & & & & \\
\hline
\end{tabular}

American Society of Anesthesiologists Physical Scale (ASA-PS) classification was available for 91\% (30,477) and Eastern Cooperative Oncology Group (ECOG) performance classification - made mandatory in the database in 2014 - was available for $90 \%(21,397)$ of the patients, the rest being recorded as "unknown". Most patients were classified in ASA-PS classes I and II (64\%) and ECOG classes 0 and 1 (82\%) (Table 1).

The medical problem was reported in all missions leading to patient contact with temporal changes represented in Fig. 6. The most common reason for response was trauma in 26\% (8897) of the missions, followed by OHCA in 20\% (6900) and acute neurological reason excluding stroke, and intoxication and related psychiatric conditions in 13\% (4366) and 10\% (3318) respectively. Of the trauma, $86 \%$ (7653) were classified as blunt and 13\% (1141) as penetrating. For the remaining $1 \%$ (103) data was recorded as "Not Classified" or "Other".

\section{Discussion}

In this study we established that gathering detailed and comprehensive data nationally on all HEMS missions while closely adhering to relevant guidelines is feasible with low rates of missing data. Key findings of this study were that in the Finnish HEMS system a large proportion of missions are cancelled or denied, and a relatively small percentage of patients are transported by helicopter. We also found that the medical problem for HEMS dispatch differ from comparable systems [7, 8, 21].

In this study we concluded that it was not possible to evaluate the validity of the recorded data. Data is entered manually by the paramedic or physician on the mission and thus errors are acceptable. This should be kept in mind when using this data. Dealing with extreme values and possible recording errors have to be taken into account in study designs. Where recording errors are suspected the data can be compared to the original documentation of the EMS or HEMS unit on-scene. This method could also be used for a future study to assess the validity of the data. This does not exclude hidden errors such as heart rate input as $96 / \mathrm{min}$ when the correct value is $69 / \mathrm{min}$. In the future electronic transfer of measurements could be used to reduce typing errors,

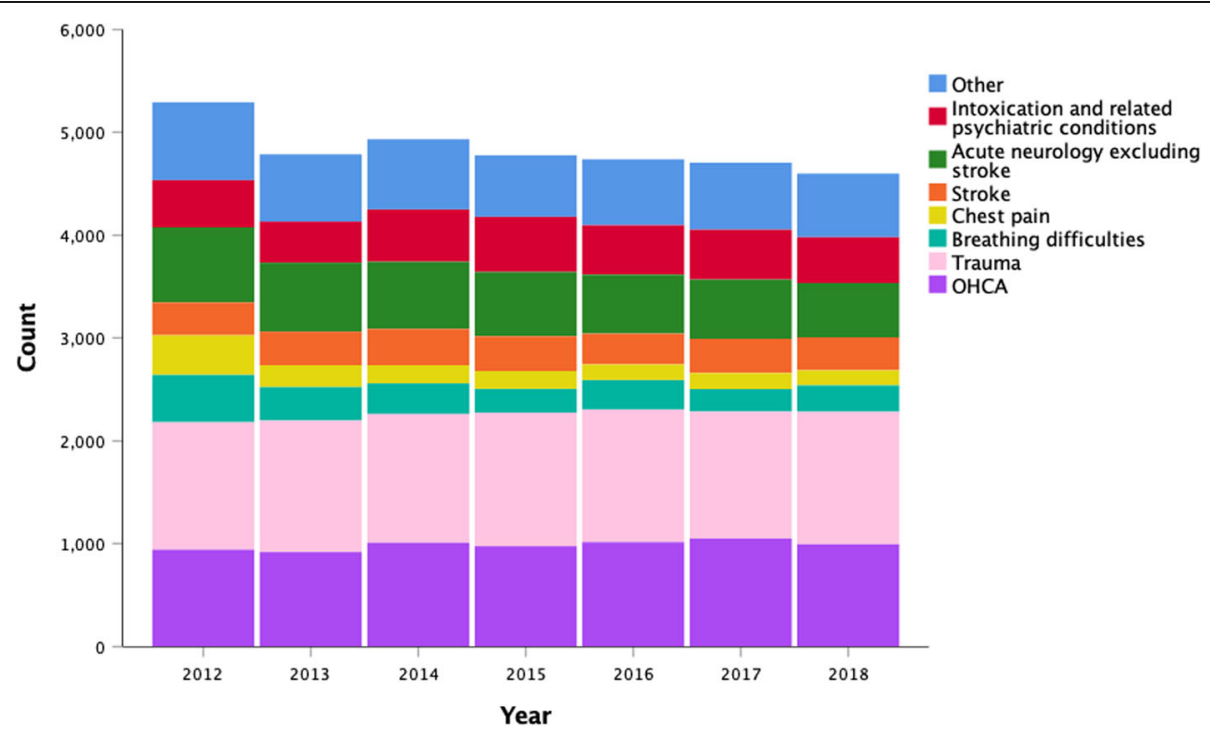

Fig. 6 The medical problem reported for patients encountered by HEMS. OHCA denotes out-of-hospital cardiac arrest 
however, this does not eliminate the errors in measurement per se.

The rate of cancelled or denied missions in the Finnish HEMS system is substantially higher than reported elsewhere $[6,7,21,22]$. Technical reliability of the service seems to be excellent and it contributed to the cancellation rate minimally. Indeed, most often the cancellation was based on the HEMS physician's judgement, following the information available from ERCO and EMS unit on the mission, that interventions by the HEMS team were not needed or that the patient would not benefit from these due to severe comorbidities etc. For patients requiring fast access to critical care to be adequately recognized, a certain amount of overtriage is unavoidable, but excessive overtriage may lead to increased costs and missing simultaneous patients that could have benefitted from HEMS [23]. Having the HEMS physician decide on a large amount of cancellations may also lead to decision fatigue [24, 25]., increasing the risk for inappropriate cancellations [25]. The effectiveness of the service could potentially be increased by improving dispatch criteria or by flight paramedic interrogation of the caller [26, 27].

Secondly, transporting a patient by helicopter in Finland is rare compared to other services [6-8]. Use of helicopter can provide significant time saving [28, 29]. with the added benefit of being able to bypass a local hospital and flying directly to an appropriate tertiarycare center [30]. HEMS has been used to transport trauma patients for a long time, but advances in invasive endovascular therapies have increased the use of aeromedical transport for patients with stroke or myocardial infarction as well. When distances are short, a rapid response vehicle is used in Finland instead of a helicopter, partly explaining the difference compared to the systems operating only by helicopter to the longer distances. Three of the six bases in Finland are located in mostly urban areas where distances are generally short and the use of helicopter might not result in time saving [31, 32]. As shown by our study, the practice of escorting a patient transported in an ambulance is more common in our system compared to other systems [6-8]. However, several studies have demonstrated benefit from timesaving by helicopter transportation in select patient groups $[28,29,31]$., raising the question whether helicopter transportation should be more frequent.

Our study also revealed marked disparities in medical problem for dispatch compared to other countries. Similarly to other systems, trauma formed the largest subset of patients. Trauma is indeed the most common cause of preventable death in the previously healthy [33]., and several studies have found HEMS to provide benefit to this specific patient group [34-36]. The second most common medical problem was OHCA, representing a large proportion compared to other systems [7, 8, 21]. A study in the Finnish population supports dispatching HEMS for OHCA [37]., but it remains largely unclear whether it incurs a survival benefit in this group [2]. Contrary to other comparable systems where stroke and myocardial infarction are common reasons for HEMS dispatch [7, 8, 21]., Finnish physician-staffed HEMS units are not usually dispatched for these missions, although encounter these patients when dispatched on different criteria, such as decreased level of consciousness. There is evidence suggesting that stroke and MI patients might stand to benefit from primary dispatch of HEMS $[29,31]$.

To provide actionable information, the data in a quality registry must be comprehensive [4]. Overall, missions recorded in FHDB had low levels of missing data. Vital signs (listed in Additional file 2) were made compulsory at the end of 2013, after which missing data rate has been very low. The initial years account for almost all of the missing data in vital signs. During this time period, missing values might be more common in critically ill patients introducing bias. However, the database offers information that can be used to assess this sort of bias, such as the physician's assessment on the seriousness of the patient's conditions. If need be, data between 2012 and 2013 could be excluded altogether. No other significant lack of values in clinical parameters were observed.

To enable multi-center research projects and comparison between systems the data has to conform to international standards. Therefore, several revisions have been made to FHDB to include variables recommended by guidelines (see Additional File 3). Most of the guidelines, e.g. airway template [9]., are followed precisely. However, not all of the core variables in the Utstein reporting template for cardiac arrest [11]. are included in FHDB as they are more appropriate to a regional cardiac arrest registry than a HEMS quality register. Despite these guidelines and increased interest in HEMS, the literature on HEMS databases is scarce and comparison between systems is challenging.

\section{Strengths and limitations}

A nationally administrated HEMS enables the maintenance of a shared, uniform database, constituting a strength of this study. The data is collected prospectively and recorded recently after mission conclusion, and the database includes every single Finnish HEMS dispatch since 2012. FinnHEMS Ltd. is funded by the government and the HEMS units are dispatched solely on medical criteria without insurance policy, wealth or socioeconomic status of the patient biasing patient selection.

As previously mentioned, the data is manually entered and not independently validated and is therefore prone to subjective factors or errors. During the existence of 
the database there have been necessary revisions on how certain variables are recorded or classified, making the analysis of trends before and after these changes challenging. Some of the recorded variables are highly subjective resulting in varying levels of disparities between providers as in any system collecting such variables, but overall a previous study found acceptable rates of interrater variability [20].

Patient selection limits the generalizability of the results. The database contains only a subset of all EMS patients and dispatching criteria in our system might omit patient groups prominent in other systems. Despite these limitations, FHDB stores a large amount of nationwide data that can be, and already has been, used for further research in prehospital EMS and HEMS [16, 18, 19]. The data is being combined with the national discharge register and mortality data, enabling studies assessing survival, factors associated with changes in mortality and length of hospitalization. Several such studies are already in progress.

\section{Conclusions}

Gathering detailed and comprehensive data nationally on all HEMS missions and treated patients is feasible. A national database provides valuable insights into where the operation of HEMS could be improved. We observed a high number of cancelled or denied missions, highlighting the need for more accurate dispatching. The low use of helicopter transportation compared to other services suggests that there might be a need to reevaluate the current practice. Nonetheless, the medical problem of encountered patients also differs from comparable systems.

\section{Supplementary information}

Supplementary information accompanies this paper at https://doi.org/10. 1186/s13049-020-00739-4

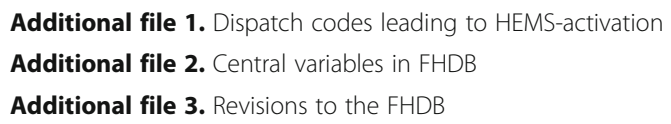

\section{Abbreviations}

HEMS: Helicopter emergency medical services; EMS: Emergency medical services; P-EMS: Physician-staffed emergency medical services; FHDB: FinnHEMS database; ERCO: Emergency response centre operator; OHCA: Out-of-hospital cardiac arrest; FH: FinnHEMS unit; HCM: HEMS crew member; SD: Standard deviation; Q: Quartile; Cl: Confidence interval; ASAPS: American Society of Anesthesiologists Physical Scale; ECOG: Eastern Cooperative Oncology Group

\section{Acknowledgements}

Not applicable

\section{Authors' contributions}

All authors participated in conceptualizing the study protocol. JB, AS, PLN, $\mathrm{AO}$ ja JN contributed to planning and execution of the study. AS and JB drafted the manuscript. JB analyzed, visualized and interpreted the data. PLN processed the database export and provided the data for analysis, contributed to data interpretation and critical revision of the manuscript. $\mathrm{AO}$ HK, PS, IP, LR and JN contributed and provided critical revisions to the manuscript. IV, HJ and TI provided critical revisions to the manuscript. All authors read and approved the final manuscript.

\section{Funding}

This research was funded by Helsinki University Hospital (state funding, VTR TYH2019243) and FinnHEMS Research and Development Unit.

Availability of data and materials

An anonymized dataset with relevant variables supporting the findings may be requested for from the corresponding author.

Ethics approval and consent to participate

Ethical approval granted by the Ethical Board of the University of Helsinki (HUS/3115/2019 §194). The study was an observational registry-based study and consent is therefore not applicable.

Consent for publication

Not applicable.

\section{Competing interests}

The authors declare that they have no competing interests.

\section{Author details}

${ }^{1}$ Research and Development Unit, FinnHEMS, WTC Helsinki Airport, Lentäjäntie 3, FI-01530 Vantaa, Finland. ${ }^{2}$ University of Eastern Finland, PO Box 1627, Fl-70211 Kuopio, Finland. ${ }^{3}$ University of Helsinki, PO Box 4, Fl-00014 Helsinki, Finland. ${ }^{4}$ Prehospital Emergency Care, Hyvinkää hospital area, Hospital District of Helsinki and Uusimaa, PO Box 585, Fl-05850 Hyvinkää, Finland. ${ }^{5}$ Emergency Medical Services, Tampere University Hospital, PO Box 2000, Fl-33521 Tampere, Finland. ${ }^{6}$ Centre for Prehospital Emergency Care, Oulu University Hospital, PO Box 50, Fl-90029 Oulu, Finland. ${ }^{7}$ Center for Prehospital Emergency Care, Kuopio University Hospital, PO Box 100, Fl-70029 Kuopio, Finland. ${ }^{8}$ Emergency Medical Services, Turku University Hospital and University of Turku, PO Box 52, FI-20521 Turku, Finland. ${ }^{9}$ Emergency Medicine and Services, Helsinki University Hospital and Emergency Medicine, University of Helsinki, PO Box 100, Fl-00029 Helsinki, Finland.

Received: 28 January 2020 Accepted: 20 May 2020

Published online: 29 May 2020

\section{References}

1. Galvagno SM Jr, Sikorski R, Hirshon JM, Floccare D, Stephens C, Beecher D, et al. Helicopter emergency medical services for adults with major trauma. Cochrane Db Syst Rev. 2015;12:CD009228. [cited 10.1.2020] Available from. https://doi.org/10.1002/14651858.CD009228.pub3.

2. von Vopelius-Feldt J, Brandling J, Benger J. Systematic review of the effectiveness of prehospital critical care following out-of-hospital cardiac arrest. Resuscitation. 2017;114:40-6.

3. Taylor CB, Stevenson M, Jan S, Middleton PM, Fitzharris M, Myburgh JA. A systematic review of the costs and benefits of helicopter emergency medical services. Inj. 2010;41:10-20.

4. Arts DG, de Keizer NF, Scheffer G-J. Defining and improving data quality in medical registries: a literature review, case study, and generic framework. J Am Med Inform Assn. 2002;9:600-11.

5. Hoque D, Kumari V, Hoque M, Ruseckaite R, Romero L, Evans SM. Impact of clinical registries on quality of patient care and clinical outcomes: a systematic review. PLoS One. 2017;12:e0183667. https://doi.org/10.1371/ journal.pone.0183667.

6. Alstrup K, Petersen J, Barfod C, Knudsen L, Rognås L, Moller T. The Danish helicopter emergency medical service database: high quality data with great potential. Scandinavian journal of trauma, resuscitation and. Emerg Med. 2019;27:38

7. Kornhall D, Näslund R, Klingberg C, Schiborr R, Gellerfors M. The mission characteristics of a newly implemented rural helicopter emergency medical service. Bmc Emerg Medicine. 2018;18:28. 
8. Rzońca P, Gałązkowski R, Wójcik-Fatla A, Panasiuk L, Gotlib J. Missions of the helicopter emergency medical service in rural and urban areas in Poland a comparative retrospective analysis. Ann Agr Env Med. 2019;26:355-60.

9. Sunde G, Kottmann A, Heltne J, Sandberg M, Gellerfors M, Krüger A, et al. Standardised data reporting from pre-hospital advanced airway management - a nominal group technique update of the Utstein-style airway template. Scand J Trauma Resusc Emerg Medicine. 2018;26:46.

10. Illid S, Lockey D, Lossius $H$, advanced airway management expert group $P$. A consensus-based template for uniform reporting of data from prehospital advanced airway management. Scand I Trauma Resusc Emerg Medicine. 2009;17:58

11. Perkins GD, Jacobs IG, Nadkarni VM, Berg RA, Bhanji F, Biarent D, et al. Cardiac Arrest and Cardiopulmonary Resuscitation Outcome Reports: Update of the Utstein Resuscitation Registry Templates for Out-of-Hospital Cardiac Arrest: A Statement for Healthcare Professionals From a Task Force of the International Liaison Committee on Resuscitation (American Heart Association, European Resuscitation Council, Australian and New Zealand Council on Resuscitation, Heart and Stroke Foundation of Canada, InterAmerican Heart Foundation, Resuscitation Council of Southern Africa, Resuscitation Council of Asia); and the American Heart Association Emergency Cardiovascular Care Committee and the Council on Cardiopulmonary, Critical Care, Perioperative and Resuscitation. Resuscitation. 2015;96:328-40. https://doi.org/10.1016/j.resuscitation.2014.11.002.

12. Jacobs I, Nadkarni V, Bahr J, Berg RA, Billi JE, Bossaert L, et al. Cardiac arrest and cardiopulmonary resuscitation outcome reports: update and simplification of the Utstein templates for resuscitation registries: a statement for healthcare professionals from a task force of the International Liaison Committee on Resuscitation (American Heart Association, European Resuscitation Council, Australian Resuscitation Council, New Zealand Resuscitation Council, Heart and Stroke Foundation of Canada, InterAmerican Heart Foundation, Resuscitation Councils of Southern Africa). Circulation. 2004;110(21):3385-97.

13. Krüger AJ, Lockey D, Kurola J, Bartolomeo S, Castrén M, Mikkelsen S, et al. A consensus-based template for documenting and reporting in physician-staffed pre-hospital services. Scand J Trauma Resusc Emerg Med. 2011;19:71.

14. Haugland $H$, Rehn M, Klepstad P, Kruger A. Developing quality indicators for physician-staffed emergency medical services: a consensus process. Scand J Trauma Resusc Emerg Med. 2017;25(1):14 PubMed PMID: 28202076. Pubmed Central PMCID: PMC5311851. Epub 2017/02/17. eng.

15. von Elm E, Altman DG, Egger M, Pocock SJ, Gøtzsche PC, Vandenbroucke $J P$, et al. The strengthening the reporting of observational studies in epidemiology (STROBE) statement: guidelines for reporting observational studies. Lancet. 2007;370:1453-7.

16. Pappinen J, Olkinuora A, Laukkanen-Nevala P. Defining a mission-based method to determine a HEMS unit's actual service area. Scand I Trauma Resusc Emerg Med. 2019;27:63.

17. Statistics Finland. Postal code area boundaries. https://www.stat.fi/tup/ paavo/index_en.html. Accessed 1 April 2018 with the licence CC BY 4.0. Available at https://creativecommons.org/licenses/by/4.0/.

18. Ångerman $\mathrm{S}$, Kirves $\mathrm{H}$, Nurmi J. A before-and-after observational study of a protocol for use of the C-MAC videolaryngoscope with a Frova introducer in pre-hospital rapid sequence intubation. Anaesthesia. 2018;73:348-55.

19. Haugland H, Olkinuora A, Rognås L, Ohlen D, Krüger A. Testing quality indicators and proposing benchmarks for physician-staffed emergency medical services: a prospective Nordic multicentre study. BMJ Open. 2019;9: e030626. https://doi.org/10.1136/bmjopen-2019-030626.

20. Heino A, lirola T, Raatiniemi L, Nurmi J, Olkinuora A, Laukkanen-Nevala P, et al. The reliability and accuracy of operational system data in a nationwide helicopter emergency medical services mission database. Bmc Emerg Med. 2019;19:53.

21. Ono Y, Satou M, Ikegami Y, Shimada J, Hasegawa A, Tsukada Y, et al. Activation intervals for a helicopter emergency medical Service in Japan. Air Medical J. 2013;32:346-9.

22. Abrahamsen E, Selvik J, Dahle A, Asche F, Abrahamsen H. A socio-economic analysis of increased staffing in the Norwegian helicopter emergency medical service. Scand J Trauma Resusc Emerg Med. 2018;26:83.

23. Madiraju G, Catino J, Kokaram C, Genuit T, Bukur M. In by helicopter out by cab: the financial cost of aeromedical overtriage of trauma patients. J Surg Res. 2017;218:261-70.

24. Pignatiello GA, Hickman RL. Correlates of cognitive load in surrogate decision makers of the critically III. Western J Nurs Res. 2019;41:650-66.
25. Pignatiello GA, Martin RJ, Hickman RL. Decision fatigue: A conceptual analysis. J Health Psychol. 2018;25:123-35. https://doi.org/10.1177/ 1359105318763510.

26. Wilmer I, Chalk G, Davies G, Weaver A, Lockey D. Air ambulance tasking: mechanism of injury, telephone interrogation or ambulance crew assessment? Emerg Med J. 2015;32:813.

27. Eaton G, Brown S, Raitt J. HEMS dispatch: a systematic review. Trauma. 2018: 20:3-10.

28. Funder K, Rasmussen L, Siersma V, Lohse N, Hesselfeldt R, Pedersen F, et al. Helicopter vs. ground transportation of patients bound for primary percutaneous coronary intervention. Acta Anaesth Scand. 2018;62:568-78.

29. Hutton CF, Fleming J, Youngquist S, Hutton KC, Heiser DM, Barton ED. Stroke and helicopter emergency medical service transports: an analysis of 25,332 patients. Air Medical J. 2015;34:348-56.

30. Mohamad N, Hastrup S, Rasmussen M, Andersen M, Johnsen S, Andersen G, et al. Bypassing primary stroke Centre reduces delay and improves outcomes for patients with large vessel occlusion. Eur Stroke J. 2016;1:85-92.

31. Stowell A, Bobbia X, Cheret J, Grandpierre R, Moreau A, Pommet S, et al. Out-of-hospital times using helicopters versus ground Services for Emergency Patients. Air Med J. 2019;38:100-5.

32. Chen $X$, Gestring ML, Rosengart MR, Peitzman AB, Billiar TR, Sperry $J$, et al. Logistics of air medical transport. J Trauma Acute Care. 2018;85:174-81.

33. Chandran A, Hyder AA, Peek-Asa C. The global burden of unintentional injuries and an agenda for Progress. Epidemiol Rev. 2010;32:110-20.

34. Michaels D, Pham H, Puckett Y, Dissanaike S. Helicopter versus ground ambulance: review of national database for outcomes in survival in transferred trauma patients in the USA. Trauma Surg Acute Care Open. 2019;4:e000211. https://doi.org/10.1136/tsaco-2018-000211.

35. Weinlich M, Martus P, Blau M, Wyen H, Walcher F, Piatek S, et al. Competitive advantage gained from the use of helicopter emergency medical services (HEMS) for trauma patients: evaluation of 1724 patients. Inj. 2019:50:1028-35.

36. Malekpour M, Younus JM, Jaap K, Neuhaus N, Widom K, Rapp M, et al. Mode of transport and clinical outcome in rural trauma: a helicopter versus ambulance comparison. Am Surg. 2017;83:1413-7.

37. Hiltunen $P$, Jäntti $H$, Silfvast $T$, Kuisma M, Kurola J. Airway management in out-of-hospital cardiac arrest in Finland: current practices and outcomes. Scand J Trauma Resusc Emerg Med. 2016;24:49.

\section{Publisher's Note}

Springer Nature remains neutral with regard to jurisdictional claims in published maps and institutional affiliations.

\section{Ready to submit your research? Choose BMC and benefit from:}

- fast, convenient online submission

- thorough peer review by experienced researchers in your field

- rapid publication on acceptance

- support for research data, including large and complex data types

- gold Open Access which fosters wider collaboration and increased citations

- maximum visibility for your research: over $100 \mathrm{M}$ website views per year

At $\mathrm{BMC}$, research is always in progress.

Learn more biomedcentral.com/submissions 